\title{
Making Sense of Game-Play: How Can We Examine Learning and Involvement?
}

\author{
Ioanna Iacovides \\ University College London \\ London \\ United Kingdom \\ +4402076792769 \\ i.iacovides@ucl.ac.uk \\ James Aczel, Eileen Scanlon, Will Woods \\ The Open University \\ Milton Keynes \\ United Kingdom \\ $+441908655581$ \\ j.c.aczel@open.ac.uk, e.scanlon@open.ac.uk, w.i.s.woods@open.ac.uk
}

\begin{abstract}
It has been argued that there is still much to be understood about the game-play experience, while there is a need for more rigorous examination of how players interact with games and the sorts of thinking they engage in during play. This paper introduces a set of methods developed to explore these issues via a multiple case-study approach. This included game-play observation, cued post-play interview, the collection of physiological data, and the use of gaming diaries over a three week period. An examination of the strengths and limitations of the approach adopted is presented with reference to two particular methodological issues: (i) how to identify breakdowns and breakthroughs that occur during game-play; (ii) how to identify learning occurring beyond game-play. The paper will conclude by emphasising the importance of taking both micro and macro-level experiences into account when investigating learning and involvement within this context.
\end{abstract}

\section{Keywords}

Involvement, Informal Learning, Play Studies, Methodology

\section{INTRODUCTION}

The gaming industry continues to expand, with different types of games appealing to wider audiences than ever before. For instance, when Call of Duty: Black Ops (Treyarch, 2010) was released, it made US\$360 million in the U.S. and the UK within 24 hours (Stuart, 2010). Further, Facebook games such as Farmville (Zygna, 2009) and technological developments such as motion control (e.g., Nintendo's Wiimote, Microsoft's Kinect) seem to have opened up games to new audiences and helped to

Transactions of the Digital Games Research Association Vol 1 No 1, ISSN 2328-9422, May 2013

(C) The text of this work is licensed under a Creative Commons Attribution-NonCommercial-NoDerivs 2.5 Generic License (http://creativecommons.org/licenses/by-nc-nd/2.5/)

IMAGES: All images appearing in this work are property of the respective copyright owners, and are not released into the Creative Commons. The respective owners reserve all rights. 
increase their cultural acceptance. At the same time, there continue to be claims made about the potential of games for learning (e.g., Gibson et al., 2010) not least because games often motivate people to devote hours to solving the challenges presented to them. However, there is a need for more "rigorous research into what players do with games (particularly those that don't claim explicit status as educational), and a better understanding of the thinking that is involved in playing them" (Squire, 2008, p.167). It can be argued that the field would benefit from investigating both how and what people learn through their involvement with games.

In order to further explore these issues, this paper reports on research which developed a set of methods for exploring how learning and involvement come together in and around instances of play. The next section introduces the relevant literature within the; this is followed by a description of the approach developed for the study. The aim of this paper is not to present specific findings, but to examine the strengths and limitations of the methods developed regarding two particular methodological issues: (i) identifying different types of breakdowns and breakthroughs that occurred during game-play; (ii) identifying learning which occurred beyond instances of game-play.

\section{RELATED WORK}

\section{Player Involvement and Learning}

One of the earliest models proposed to account for involvement in games comes from Malone and colleagues who proposed a theory of intrinsic motivation. This was derived from experimental manipulations of drill and practice games that suggested that games are rewarding because of the ways in which they combine the elements of challenge, fantasy, and curiosity (Malone, 1981). Later work (Malone and Lepper, 1987) also added the element of control, as well as further interpersonal motivators (recognition, competition and cooperation). However, it has been argued that, despite the later inclusion of interpersonal motivators, there is too narrow a focus on the structure of the game itself, without sufficient attention being paid to the social dynamics that occur around it and to the context within which the game itself is played (Egenfeldt-Nielsen et al., 2008).

Another general theory of motivation, which has recently been applied to games (Ryan, Rigby, and Przybylski, 2006) is self-determination theory (SDT). Ryan et al. (2006) suggest that people play in order to satisfy our psychological need for: competence (need to experience challenge), autonomy (sense of volition), and relatedness (feeling connected to others). While relatedness does suggest a social reason for becoming involved in games, it could be argued that this theory still tells us little about the context in which this involvement occurs. Further, neither the work of Ryan et al. nor that of Malone and colleagues appears to tell us much about how involvement relates to any learning that results from game-play.

One model which does suggest how involvement and learning affect each other is the Digital Game Experience Model (DGEM; Calleja, 2007). In later work this model is referred to as the Player Involvement Model (Calleja, 2011). Specifically, Calleja distinguishes between "macro-involvement" which refers to "motivational attractors to games that influence sustained engagement through the long-term" and "microinvolvement" which refers to "the moment-by-moment involvement of the game-play instance" (Calleja, 2007; p. 237). The macro-level can be used to consider activities that occur around play, while the micro-level refers to the experience of play itself. This 
distinction allows for a discussion of the learning and involvement experienced during play (e.g., Iacovides, 2009; suggesting that deeper levels of involvement actually depend on how the player internalises, i.e., learns about, different aspects of the game). Further, the model can be used to consider how activities that occur outside of the moment of game-play (e.g., using a walkthrough or discussing a game with friends) might affect longer term motivations.

Gee (2004) addresses the issue of how people learn through their involvement with games, by providing an account based on his own observations and semiotic analysis. He argues that when people play games they are actively engaged in the process of learning a new literacy. This literacy includes multi-modal texts and graphical representations. Through gaming, players learn to participate in semiotic domains made up of words, pictures, and/or anything else that is used to communicate meaning. These domains are associated with specific affinity groups of players whose knowledge, skills, tools, and resources contribute to form complex systems of distributed parts. These groups could be considered a community of practice (Lave and Wenger, 1991), where learning occurs when players gain resources from fellow members to help them to solve problems within, and sometimes outside of, the specific domain. Gee (2004) uses the term critical learning to refer to the learning experienced when the player starts to consider "the domain at a "meta' level as a complex system of interrelated parts" (p. 23). He also argues that critical learning involves not just a change in practice, "but in identity" (p. 190). He goes on to discuss the learning that occurs through the adoption of and experimentation with different identities, as well as through the ability to reflect upon the relationship between old and new ones.

However, Pelletier and Oliver (2006) argue that while Gee provides a strong account of how learning through games can occur, he does not provide researchers with the tools for examining different games and contexts. Further, they point out that the literature in the area lacks "a method that looks at the process and outcomes of play, explaining how this relates to the design of the game as well as the social and cultural aspect of play" (p. 331). It could also be argued that the area would benefit from further empirical research to substantiate Gee's semiotic analysis. Thus, there is a need to develop methods which can be used to examine the different ways in which involvement and learning actually do come together in and around instances of game-play.

\section{Considering Wider Activities}

In order to explore in more detail the activity that occurs around game-play (through player involvement on a macro-level), the concept of gaming capital can provide useful insights. Consalvo (2007) developed this concept from Bourdieu's (1984) notion of cultural capital in order to

Capture how being a member of game culture is about more than playing games or even playing them well. It's being knowledgeable about game releases and secrets, and passing that information on to others. It's having opinions about which game magazines are better and the best sites for walkthroughs on the Internet (p. 18).

Consalvo discusses the ways in which paratexts help players to acquire gaming capital. Paratexts are external resources that can "surround, shape, support, and provide context for texts" (p.182). So, in this context, games themselves constitute the primary texts, while examples of paratexts include walkthroughs, reviews, YouTube videos, blogs, and 
magazines that relate to games. Players can thus increase their knowledge about games and game-play practices by consulting these various resources. Both the concept of gaming capital and the idea of paratexts can be helpful for considering involvement and informal learning in relation to community membership. To use Gee's terminology, gaming capital might help explain why players choose to participate in different affinity groups and semiotic domains.

\section{Evaluating Game-Play}

There are numerous different ways in which researchers have tried to evaluate aspects of the game-play experience. For instance, Pelletier and Oliver (2006) used a small-scale case-study approach to present a method for examining how people learn to play games. Using an approach based on Activity Theory (Kuutti, 1996), they decided to decompose activities into actions and operations and to take note of any contradictions (i.e. breakdowns, problems) that occurred. This allowed them to identify and discuss the strategies players adopted but focusing purely on the game-play meant that they had to make certain inferences about what players were trying to do. As a result, it is difficult to gauge the extent to which the inferences the authors made actually governed players' behaviour within the game.

Ryan and Siegel (2009) also used the concept of breakdowns for examining game-play and drew upon the earlier work of Marsh et al. (2001), by making a distinction between a breakdown in interaction and a breakdown in illusion. Breakdowns are generally described as occurring "when actions we take to accomplish something no longer seems [sic] to work" (p.1). The term breakdowns in interaction refers to what they call "the natural breakdowns" that lead to learning within the game; breakdowns in illusion refers to a loss of immersion (in terms of absorbed attention). Ryan and Siegel argue that the former are part of normal game-play but, unlike the latter, they do not disrupt the experience of flow. As a result of their analysis of game-play, they present four main categories of breakdown (which relate to perceiving the environment, developing strategy, taking action, and meaning-making), though they do not make a point of indicating which of them (and their associated subcategories) are breakdowns of interaction or of illusion. They seem to imply that most stem from interaction issues but that some of these can also lead to further breakdowns in illusion. In recent work, Sharples (2009) adopts a different focus, using critical incident analysis to identify breakdowns and breakthroughs in order to gather mobile technology design requirements within an educational context. In this instance, breakdowns are "observable critical incidents where a learner is struggling with the technology, asking for help, or appears to be labouring under a clear misunderstanding," while breakthroughs are "observable critical incidents which appear to be initiating productive, new forms of learning or important conceptual change" (p. 10).

There has also been interest in using physiological measures to examine players' emotional reactions to game-play. For instance, Mandryk and colleagues tested the efficacy of using physiological data to evaluate entertainment technologies. They found that galvanic skin response (GSR) was able to distinguish between conditions that involved playing a game with a friend and conditions that involved playing against a computer (Mandryk and Inkpen, 2004). They also suggested that this kind of data can be used to provide a continuous, objective measure of emotional experience (Mandryk and Atkins, 2007), though this is still a time-consuming and complex approach to adopt and it is not always clear which emotions are being modelled. Further, their findings are based on five-minute episodes of playing a sports game within a lab environment. Although this 
makes sense for the in-depth analysis appropriate to their study, such a setup does not seem particularly representative of typical console-play activity. A definitive model of emotion derived from these physiological signals has yet to be established, but Hazlett (2008) does suggest that this kind of data can be used in real-time to indicate when significant instances have occurred, which the player can then be asked about afterwards.

It appears that there are a number of ways in which to examine different aspects of the game-play experience, but there is still a lack of studies that look at both micro and macro-level involvement over longer periods of time, especially in relation to learning. An exploratory, mixed-method, case-study approach would be helpful in furthering our understanding of how involvement and learning come together in and around episodes of game-play (Iacovides et al., 2011a).

\section{METHODOLOGY}

\section{Research Questions}

The study discussed in this paper is part of a larger project that aims to explore the relationship between motivation, engagement, and informal learning that occurs through playing digital games (reported in Iacovides, 2012). For purposes of this research, Calleja's definition of involvement was adopted (Calleja, 2007). More specifically, the term micro-involvement is used to refer to player engagement during episodes of gameplay, and macro-involvement is used to discuss players' general motivations and gamingrelated activities that occurred outside the instance of play. In this case, learning refers to the informal learning that is a result of gaming activities, whether players achieve this alone, or through collaboration with others (directly or indirectly through the use of paratexts). In Vavoula et al.'s (2005) terms, this sort of learning is informal in the sense that it takes place outside of a formal context (where a teacher would normally define learning goals and processes) and in most circumstances it could also be called unintentional since learning is unlikely to be the main goal of play.

In order to gain a better understanding of how involvement and learning come together in practice, the study described addressed the following questions:

1. How can we identify breakdowns that occur during play?

a. How do players attempt to resolve these breakdowns?

b. What role do breakthroughs play in this process?

2. What can examining breakdowns and breakthroughs tell us about how involvement and learning come together in practice?

3. What evidence is there that players are learning in addition to learning how to play?

The purpose of this paper is to focus on the methods developed and to evaluate how useful they were for addressing the research questions listed above. The findings are reported elsewhere (Iacovides et al., 2011c; Iacovides, 2012). The following sections describe how the study was carried out. Examples from the case studies will subsequently be used to illustrate how useful the methods were for identifying (i) breakdowns and breakthroughs and (ii) evidence of learning that occurred beyond instances of play. The paper will conclude with a reflection on strengths and weaknesses of the approach and an outline of future work. 


\section{Design and Participants}

In order to address the research questions, investigators adopted an exploratory casestudy approach, involving the use of multiple methods. The approach was adapted from previous work carried out by Iacovides (2009), who used cued retrospective reports to examine learning with respect to micro-level involvement. Yin (2009) argues that collecting multiple sources of data helps to increase validity when using a case-study approach, while reliability can be ensured by following a case-study protocol. Using a protocol ensures that the researcher follows a similar procedure in each case; so a protocol was developed for the first author to follow during each lab session and interview.

Eight cases were completed, with nine participants in total (ages 23-59; five male, four female). Seven cases consisted of a single participant who came into the lab on three occasions and kept a gaming diary over a three-week period; the eighth case consisted of two participants, a married couple. The couple were included in order to test the efficacy of the method in dealing with more than one player and to consider some of the social influences that might affect involvement and learning. Investigators recruited players from a previous email interview study (Iacovides et al., 2011b). Players differed in terms of age and in how they identified as gamers (a mix of casual and more serious gamers was selected), with the aim of maximising the differences between cases as far as possible (Stake, 2003). The lab was set up as a comfortable living room environment, with a couch, a wide-screen TV, and game consoles for the use of the participants.

\section{Procedure and Methods}

A variety of methods was used, including observation, post-play interview, the collection of physiological data, and the gaming diaries kept by participants for three weeks. The physiological measures were chosen on the basis of research carried out by Mandryk and colleagues (e.g., Mandryk and Atkins, 2007). The data was collected using the ProComp Infiniti system and sensors, with BioGraph Software from Thought Technologies. Galvanic skin response (GSR) was collected with surface electrodes snapped onto Velcro straps worn around the index and ring fingers. For electrocardiography (EKG), three pregelled surface electrodes were attached in the standard configuration of two on the chest and one on the abdomen. Heart rate is calculated from this EKG signal. For electromyography (EMG), surface electrodes were used on the jaw (indicative of tension), cheek (indicative of smiling), and forehead (indicative of frowning). Three electrodes preconfigured in a triangular arrangement were used on the jaw and cheek, while separate extender cables were used for the forehead. Facial and body hair can interfere with the EKG and EMG signals; participants were screened to avoid this possible problem.

Participants were asked to come into the lab and be observed as they played on three separate occasions. The first session was mainly introductory, consisting of a preliminary interview and an introduction to the physiological equipment. The participants also filled in a short questionnaire about gaming habits and preferences and signed a consent form. They had been asked to bring in a game of their choice to play in the lab for 15 minutes during the first session; this was intended to familiarise them with the physiological equipment and the procedure they would be following in subsequent sessions (during which they would be playing for up to an hour). A three-minute baseline measure for the physiological recordings was taken before and after the game-play sessions, for comparative purposes. During game-play, the first author observed the session from a separate room with camera feeds of the player and the game-play as well as the player's 
physiological reactions. After the game-play, the investigator reviewed the video recording with the participant so that they could discuss what the player had been thinking and feeling during the session. Tea or coffee and biscuits were provided during the post-play interview to help make the experience more comfortable and relaxed.

The second session took place the following week; again, the participants were asked to bring in what they were currently playing. Care was taken to ensure that players could continue their progress from the last time they had played by either transferring a saved game file to the lab console or asking them to bring in their own console to play on. The rationale for this was to tap into an experience in which the players were genuinely motivated to play a game. In the third session, the players were asked to play a game that they had not played before, which was also the sort of game they were unlikely to pick for themselves (selected for them on the basis of the preliminary interview). The purpose of this was to examine what happened when they played something unfamiliar, though care was taken to make sure they had no objections to the first author's choice. Sessions lasted between two and three hours.

Finally, participants were required to keep a paper-based diary of their game-playing and game-related activities over the period of the study. This diary included questions to prompt the participants; so, in addition to asking them to take note of what they played every day and for how long, the questions also covered what they did when they got stuck, who they talked to about games, whether they visited or contributed to paratexts (websites, forums, etc.), and whether they thought they had learnt anything from their activities. The diaries were intended to keep track of game-play which occurred outside the lab and to provide an indication of macro-level involvement. The study concluded with a final semi-structured interview (lasting 30 minutes to an hour) which was based on the diary entries. The diary-interview method is explained in further detail by Elliot (1997). Participants received a £15 Amazon voucher (approximately 17 Euros or 24 US dollars) to thank them for their participation in the study.

\section{Analytic Process}

In order to examine the video recordings, investigators used transcriptions of the postplay interviews to identify initial breakdowns and breakthroughs. INTERACTTM (Mangold International $\mathrm{GmbH}$ ), a video analysis tool, was then used to code the multiple data streams (see Figure 1) in terms of the various breakdowns and breakthroughs that occurred.

The first stage of the analysis involved examination of a player's micro-level involvement. The physiological data was originally intended to signal significant instances to the investigator, which could then be followed up during the post-play interview; as suggested by Hazlett (2008). However, it was particularly challenging for a single observer to keep track of the several physiological reactions while simultaneously watching the camera views of the player and the game-play. For this reason, it was decided that it would be more suitable to use the data during the post-play analysis in order to pinpoint significant episodes and issues. Unfortunately, this also proved to be unfeasible due to the large amount of data collected within each session, where frequent changes would occur within the 30 to 60 minute episodes. Further, given that these signals can vary greatly between individuals and that many of the larger changes were actually due to movement artefacts (rather than being the result of the player reacting to in-game stimuli), it was not clear how to establish whether a change was significant or 
not. Even though baseline readings were taken prior to each session, all that can be said is that players did show more physiological activity during game-play than they did at rest.

Therefore, a final attempt was made to examine the physiological data in relation to specific episodes which had been deemed significant on the basis of the post-play interview data. However, this was not successful either, due to the difficulty of interpreting the signals and establishing meaningful patterns in relation to the different types of breakdown and breakthrough. As Kivikangas et al. (2010) point out, games are much more complicated stimuli than those adopted within previous psychophysiological research (e.g., where reactions are measured while participants view a sequence of standardised images). Further, despite the claim that these signals can provide an objective measure of the player experience (e.g., Mandryk and Atkins, 2007), they still have to be interpreted - and this is not a simple task (Isbister et al., 2007).
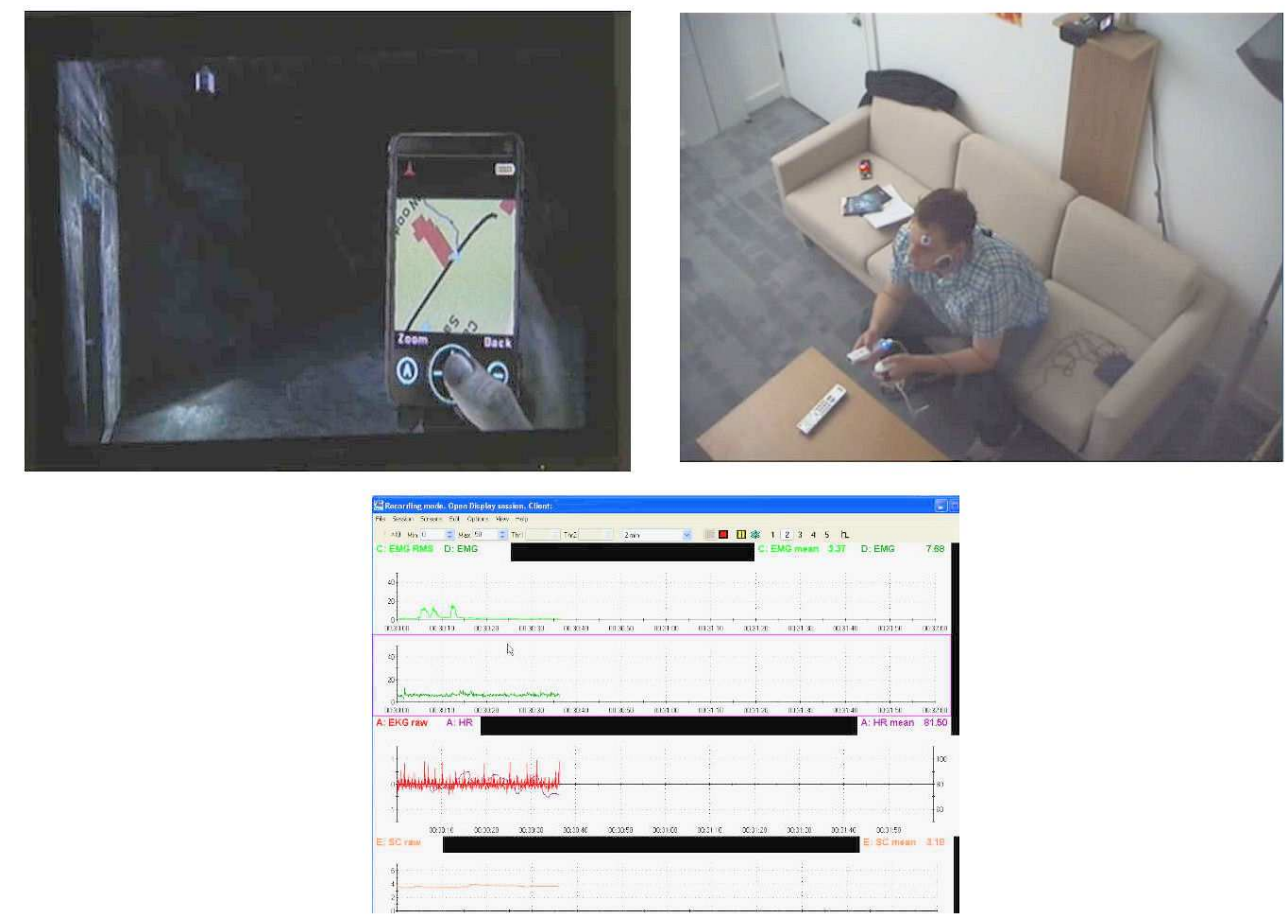

Figure 1: Video recordings of the game-play, the player, and the physiological readings (Case 1: Matt playing Silent Hill: Shattered Memories).

In order to provide an illustration of how using this sort of data proved challenging under these circumstances and how it did not help with identifying breakdowns and breakthroughs, two examples are provided below.

Figure 2 shows an extract from Linda's (F, 59) session playing Lego Indiana Jones 2 (Traveller's Tales, 2009). This example indicates the range of individual differences. Linda would frequently talk to herself during the session, and sometimes hum the theme tune, but even in quieter moments, she showed much more EMG activity than the other participants. The figure below shows Linda's physiological activity for part of the section of the game when she returns to the main hub in between levels. The top graph represents 
EMG cheek activity, the second EMG forehead, the third EKG and heart rate, and the bottom graph shows GSR.

The first vertical dotted line (in bold) represents Linda's exit from the previous area, while the second indicates when she leaves the hub. At 18.45, Linda realises that she has not discovered a new part of the game and becomes frustrated, stating during play: "Back here again? How on earth did that happen?," she confirmed had made her "cross" when discussing the episode in the post-play interview. This frustration does seem to correlate with increases in GSR and EMG cheek and forehead, but several of the other peaks are less easy to interpret. While some of the heightened EMG activity (for both cheek and forehead) can be attributed to movement and speech (e.g., at approximately 20.05, Linda sighs quite loudly), much of it seems to occur without an obvious cause.

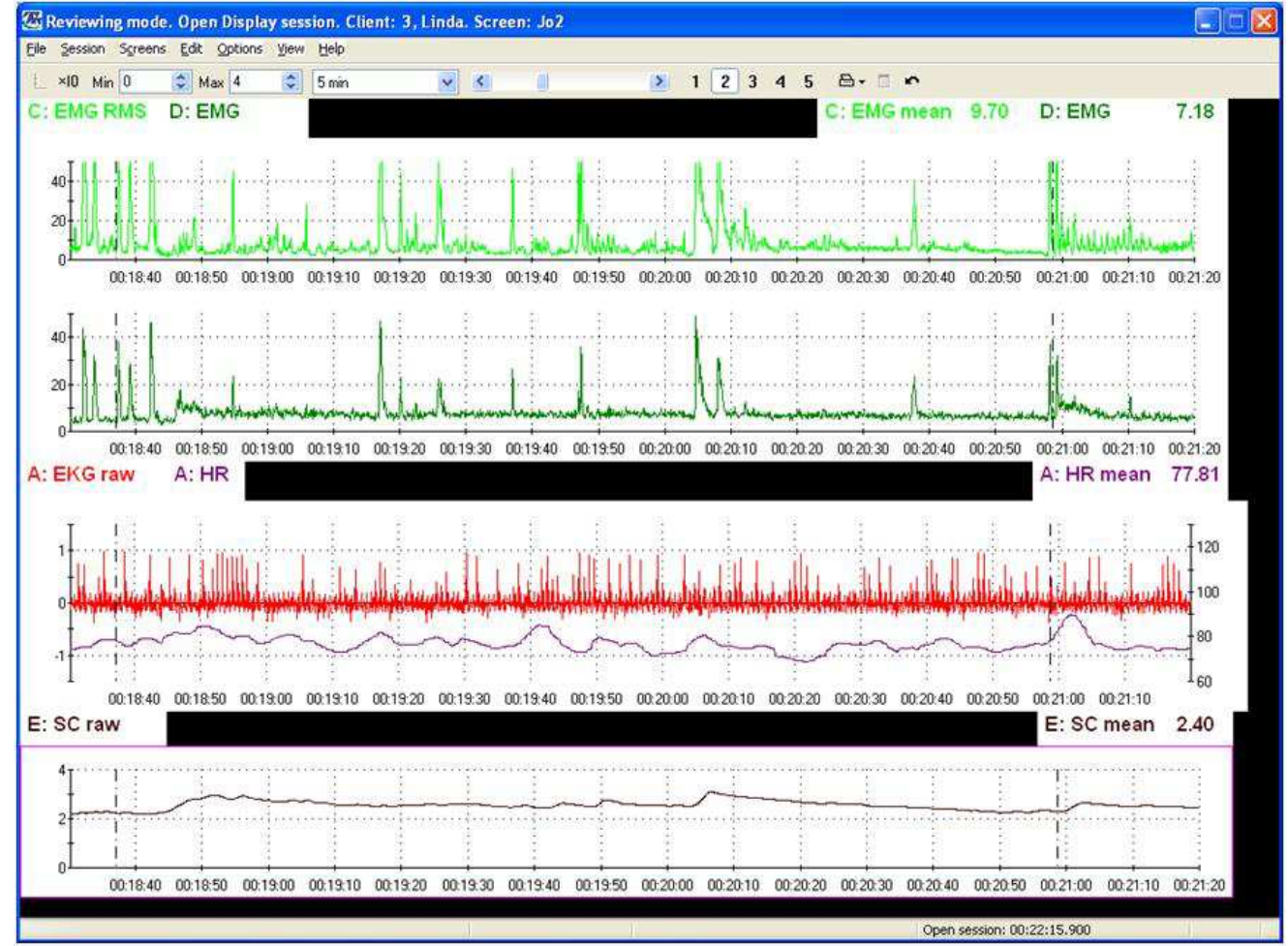

Figure 2: Linda playing Indiana Jones 2.

In contrast to Figure 2, Figure 3 illustrates Alex's (M, 41) physiological data from a particular episode of Flower (Thatgamecompany, 2010), in which he showed very little physiological reaction, despite experiencing multiple breakdowns during this time. While the first vertical dotted line indicates a small change in EMG cheek and heart-rate activity - seemingly as a result of a short animation (unlocking a new part of the area for him to explore) - Alex appears to show little reaction to the rest of the canyon sequence (the second dotted line represents the end of this section). This is in spite of the fact that he often missed the petals he thought he had to collect, felt "disconcerted" by part of the sequence, and got a bit "fed up" with aspects of the game during this time. 
In short, movement artefacts, the difficulty of interpreting the data in relation to specific stimuli and the lack of consistent patterns observed within the sessions meant the signals did not prove useful for identifying the breakdowns and breakthroughs which occur during game-play. Existing research has examined these signals as the basis for modelling emotion (e.g., Mandryk and Atkins, 2007) and for distinguishing between positive and negative emotions (e.g., Hazlett, 2008), on the basis of experiments using controlled conditions. However, even if an experimental approach were adopted, the analysis indicates that physiological data is not particularly helpful for pinpointing breakdowns and breakthroughs.

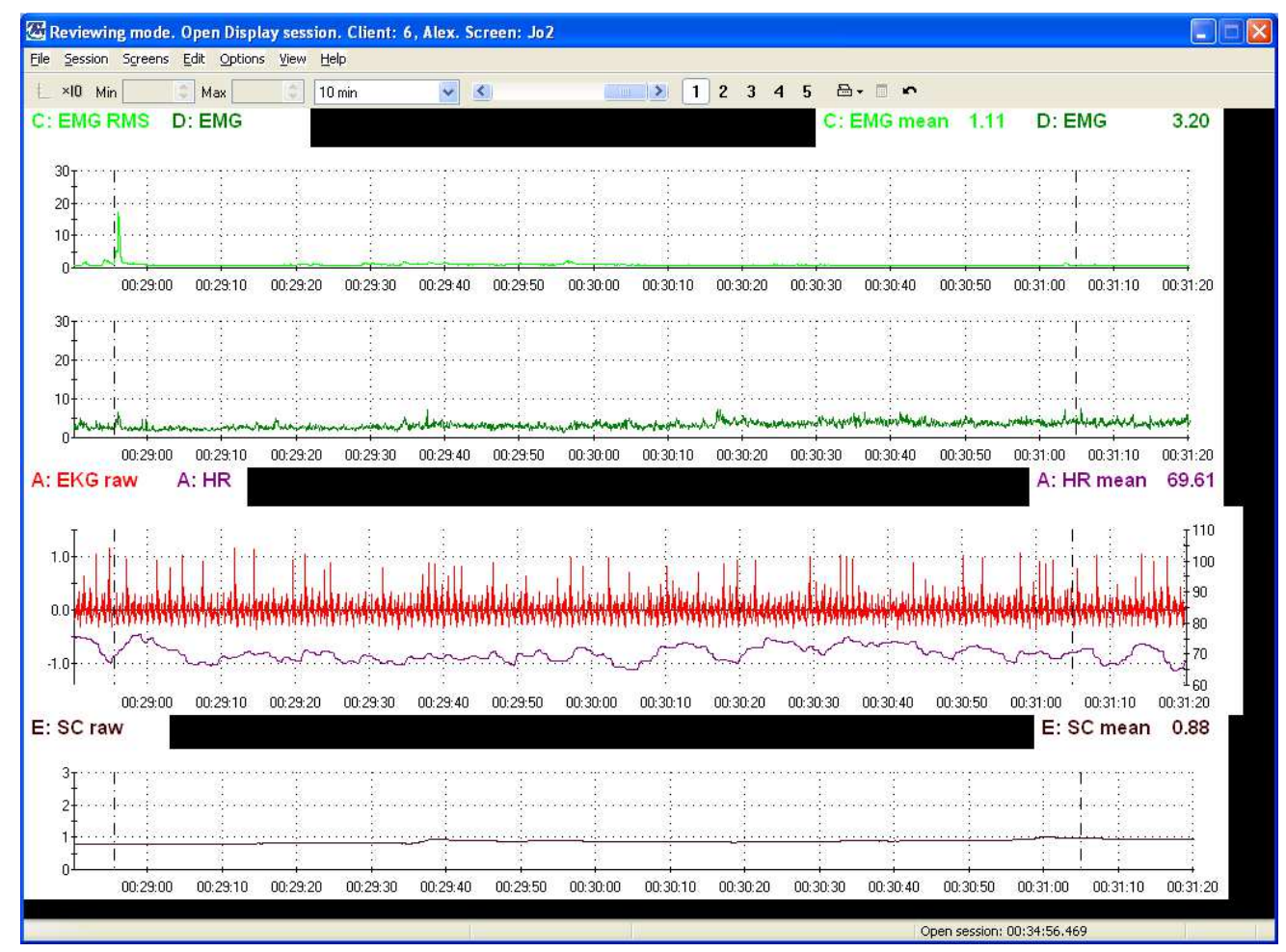

Figure 3: Alex playing Flower.

Further, there is another potential confound that requires attention, and this is the impact that being observed can have on the player. For instance, Amy (F, 28) would often laugh when playing Mario Kart (Nintendo EAD, 2008) - usually when something negative had happened. When questioned about it, Amy suggested that "If I'd been on my own, I might have just got annoyed," but because she was aware of being watched, "I guess you kind of go, well I'm not going to get annoyed, so, I may as well just find it amusing. As an alternative emotional response to the stupidness that is this game." This raises an issue in terms of whether the physiological reactions which are being reported in the literature really do represent some of the emotions researchers are attempting to investigate, or whether they are in fact indicators of some people's complex emotional reaction to playing a game while knowing someone else is monitoring their behaviour.

The final stage of analysis involved the examination of the gaming diaries. The handwritten diary entries were typed up into Microsoft Word documents and the diary 
interview was transcribed so that Nvivo 8 software could be used to analyse these transcripts. Particular attention paid to identifying breakdowns and breakthroughs that occurred during game-play sessions outside of the lab. The emphasis was on identifying macro-level interactions (e.g., looking at gaming websites or guides) and any evidence that suggested learning occurring beyond learning how to play. This analysis also included the application of prior themes, developed in an earlier study, that relate to the concept of gaming capital (Iacovides et al., 2011a) and categories that relate to learning (Iacovides et al., 2011b).

\section{METHODOLOGICAL ISSUES}

This section offers a reflection on the method developed. Some examples from the case studies will be presented below in order to illustrate the degree to which the adopted methods were able to capture the following methodological issues.

\section{(i) Identifying Breakdowns and Breakthroughs That Occurred during Game- Play}

The main focus of the video analysis was on coding for the different types of breakdowns that occurred during play, the attempts made to overcome these breakdowns, and any breakthroughs that occurred during these attempts. The breakdowns and breakthroughs were subsequently classified as major or minor, and then discussed by the authors in order to establish which ones could be regarded as involving important episodes and underlying issues. While this was a time-consuming process, utilising the video recordings in conjunction with the post-play interview transcripts was very useful for capturing large amounts of rich evidence concerning the different types of breakdowns and breakthroughs that occurred. As stated earlier, the physiological data was not found to be useful for identifying breakdowns and breakthroughs.

The following case-study example illustrates how the methods were applied. When Matt (M, 24) was playing Silent Hill: Shattered Memories (Climax Group, 2009), he entered a part of the game which he referred to as the nightmare realm and soon found himself being chased by monsters. There are no weapons within the game, so he had to come up with different ways of avoiding these monsters. Soon after he entered this realm, it became apparent that Matt was having trouble doing that and in terms of navigating through the environment. This soon led to his character's death and his having to start again from the last save point; this was identified as an important episode. It seemed clear that this failure frustrated Matt, not so much because his character had died, but because he did not think he had done anything wrong: "I just got trapped, I went under the bed but he found me, twice, and then I'm trying to run away, which is a dead end anyway, and as soon as one found me, all three found me, which was quite annoying. I was, like, that's not fair at all." This suggests that Matt was experiencing breakdowns on numerous levels: as his attempts to avoid the monsters were unsuccessful, he did not understand why his actions were unsuccessful; and he subsequently experienced a loss of agency, where he saw the game as being at fault rather than himself. However, after this episode, Matt started to develop more effective ways of dealing with the monsters, and also experienced a breakthrough in understanding when he realised that the GPS function on his character's phone (see Figure 1) also indicated the location of the monsters.

Nevertheless, Matt still did experience difficulties with navigating through the environment as minor breakdowns. Due to the pressure of being chased through parts of the nightmare realm which looked very similar, he often felt unsure about where he was going. After a while, he found himself in a new area: "I was quite happy to see outside 
because I wasn't just running round in circles through doors." This new area arguably resulted in a breakthrough in terms of involvement since it was seen as confirmation of progress, despite Matt being unsure about how he had reached this point. Interestingly, his uncertainty suggests he was able to progress within the game, but without experiencing a breakthrough in understanding - something considered further in Iacovides (2012).

Finally, the diary entries allow us to track Matt's experience with Silent Hill over time, illustrating how little he played the game, especially in comparison with how often he played Metro 2033 (4A games, 2010) in the same time period. The diary interview also gives us further insight into why he gradually lost interest Silent Hill. Despite initially being intrigued by the narrative, he grew frustrated with the mechanics. In short, he felt the game-play in the nightmare realm was "a bit arbitrary" because "when you got chased, you couldn't really do much about it," and so it ended up at "the bottom of the list" of what he wanted to play. The lack of agency he expresses suggests that Matt experienced a fundamental breakdown in involvement and soon lost interest in the game.

As Matt's case indicates, the diaries were another source of evidence concerning breakdowns and breakthroughs, though due to their retrospective nature the evidence they provide is far less detailed than that provided by the video and post-play interview data. On the plus side, they can capture more naturalistic events since they refer to activity outside of the lab. For instance, Natasha (F, 31) notes an episode that occurred when she was playing Doctor Who: The Adventure Games (Sumo Digital, 2010), in which she experienced a breakdown in the form of not being able to get past the Dalek enemies without getting shot. She "tried two or three times before giving up and handing the game over to William" (her husband) as she found the controls "very fiddly"; though she watched him play for another half-hour, she soon grew "bored" with it. It is interesting to note that, during the three-week study period, neither Natasha nor William reports playing this game again. In another case, Linda $(F, 59)$ reports breakdowns beyond her control when experiencing server problems while trying to play Farmville (Zynga, 2009). She also discusses getting stuck on a couple of occasions when trying to solve the murder mystery puzzles in Broken Sword: The Shadow of the Templars (Revolution Software, 2009). In the latter case, she used the in-game hint system as a "prompt" in cases where she felt the "brain gets into a stuck groove and lateral thinking [is] usually needed." This is an example of how the game itself can facilitate breakthroughs that are necessary for continued progress.

\section{(ii) Identifying Learning beyond Instances of Game-Play}

The diary entries were also able to capture player interactions with paratexts, such as when Matt looked up a forum post about the various weapons he could buy in Metro 2033 , in order to try and find out which ones he should save up for within the game. These interactions also included such instances as Matt regularly checking Reddit games (a site aggregator) to keep up-to-date on the latest gaming news. Here, Matt was accessing the wider gaming community for knowledge about new releases and developments within the industry. Further, Matt's use of paratexts relates to the concept of gaming capital, in the sense that he already seemed to know how to access the information he wanted; as a gamer, he likes to keep up to date about different gaming developments.

Another example of how the diaries captured learning outside of game-play concerns Justin (M, 32), who ended up looking up some general knowledge after playing God of 
War III (Santa Monica Studio, 2010) in order to find out more about Greek mythology and "some of the more obscure characters in the game." This is also a good example of learning through tangential resources (as opposed to paratexts) since it illustrates how a game experience can inspire curiosity and the urge to learn about something beyond the level of the game.

The diaries were also able to capture the development of collaborative skills, as when Linda played drums on Guitar Hero 5 (Neversoft, 2009) with her daughter, who played guitar, as a reward after doing housework. In addition, the interviews were used as an opportunity for participants to talk about their general gaming activities over time, so that while Alex (M, 41) frequently mentioned playing with his son in the diary entries, it became clear from the interview that they would frequently bond over game-play and use the episodes to discuss other issues, such as the fact that using walkthroughs can be helpful, but it can be more rewarding when you put more effort into activities and succeed on your own.

While the diaries were useful for capturing activities outside of the lab and the final diary interviews provided richer descriptions of these activities, some of the evidence for learning that occurred beyond learning how to play surfaced also during the observation and post-play interview phases of the study. For instance, it became clear from Katy's (F, 23) interview about her session playing Zelda: Twilight Princess (Nintendo EAD, 2007) that she had developed a strong empathy for the character. She used the phrase "Poor Link" on several occasions; this was usually a response to the character Link dying within the game, but she discussed aspects of the narrative as being "really sad" when you considered them from his point of view. Further, she reflected on how there had been times when she acted within the game in specific ways because "that's the way Link would do it," but sometimes she did things "just out of curiosity." For example, at one point she talked to all the characters within an area because, even though "Link would probably run straight through the door," she wanted to see what they had to say. Though this was a rare occurrence, this sort of thinking is a good example of what Gee (2004) seems to be referring to when he talks about the critical learning that occurs when players consider the relationship between their individual and virtual identities.

\section{DISCUSSION}

In order to explore how player involvement and learning come together in and around instances of game-play, a multi-method, case-study approach was developed. This paper has sought to address two specific methodological issues: (i) how to identify different types of breakdowns and breakthroughs that occur during game-play; and (ii) how to identify learning which occurs beyond game-play.

In terms of issue (i), the physiological data did not prove useful for identifying breakdowns and breakthroughs. Further, while the video recordings of the game-play and player could have been relied on to identify various breakdowns and breakthroughs that occur on a micro-level, without the post-play interview, investigators would have had to make certain inferences about the nature of these. For instance, when Matt died in Silent Hill, it would have been reasonable to assume that the fact of dying had annoyed him, especially in conjunction with the footage of him shaking his head afterwards and saying "I don't know" just after the event. However, the underlying issue here would have been missed. Matt was not annoyed because he had died; he was annoyed because he didn't understand why he had died. This breakdown in understanding was compounded by his general confusion about where he was supposed to go, even though he experienced some 
minor breakthroughs in the form of developing new strategies. The diary entries also allowed for insight into players' involvement over time, such as Matt's giving up on Silent Hill. Further, while the lab was set up for console game-play, the diaries were able to capture game-play on other devices, including computers, handheld consoles, and mobile phones, which could then be discussed in the final interview. Collecting data from multiple sources helped in terms of triangulating the data for identifying breakdowns and breakthroughs, and this in turn allowed for a more in-depth understanding of how these breakdowns and breakthroughs occur over time.

In terms of issue (ii), the methods developed allowed investigators to gain further insight into the learning that occurred beyond instances of play, in terms of players' macro-level involvement with games. The diaries enabled us to take into account player involvement with external resources, such as game paratexts; which were consulted for game advice and for keeping up-to-date with general gaming developments. The diaries also captured instances of players further exploring information they had encountered within a gamee.g., Justin looking up aspects of Greek mythology. Keeping up-to-date with gaming news and looking up further information can also been seen as examples of learning beyond the experience of learning how to play. The final interview based on the diary entries also meant participants could elaborate on instances of game-play, and this was especially useful for considering participant involvement in wider gaming activities. In addition, by asking participants to bring in a game of their choice, and to further discuss this choice during the interviews, we were able to gain a deeper understanding of their involvement and learning than would have been possible from just observing a session of game-play. For instance, Katy chose to bring in Zelda: Twilight Princess as she had decided to replay it, much like "re-reading a favourite book." Both the post-play and the diary interviews revealed that she had a long-running involvement with the Zelda series, suggesting that the empathy she displayed for the characters was something that had developed as a result of years of playing Zelda games and engaging in game-related activities such as role-playing and writing fan fiction. Again, the method allowed not only for triangulation of data, but also for a consideration of a player's history and the different kinds of learning and involvement that occur over time.

However, there are limitations to this approach. The most obvious disadvantage is the amount of time required to conduct the study and analyse the data. Further, it should be noted that while the introductory session and the length of the main game-play sessions helped participants feel at ease within the lab, some did report feeling aware of the fact that they were being observed. Finally, as this is a case-study approach, care must be taken when statistical generalisations and comparisons between sessions are made. Nevertheless, as Yin (2009) argues, the aim of a case-study approach is "to expand and generalise theories (analytical generalization) not to enumerate frequencies (statistical generalisation)" (p. 15). Thus the findings can be considered in terms of general theoretical propositions about how involvement and learning relate to each other (see Iacovides et al., 2011c; Iacovides, 2012).

This paper illustrates how the methods described were able to capture a range of issues relating to involvement and learning. By looking for general patterns across the rich and informative data set, we can gain a deeper understanding of how involvement and learning come together in and around instances of game-play. It is only through taking both macro and micro-level experiences into account that we can really address just "what players do with games" and "the thinking that is involved in playing them" (Squire, 2008; p.167). 


\section{ACKNOWLEDGMENTS}

This research is funded by the Economic and Social Research Council, UK as part of a 1+3 studentship. We would like to thank all the participants for taking part in the project, and to thank Mangold International $\mathrm{GmbH}$ for the software, INTERACT ${ }^{\mathrm{TM}}$.

\section{BIBLIOGRAPHY}

4A Games. Metro 2033 [Xbox 360], THQ, 2010. Played April 2010.

Bourdieu, P. Distinction: A Social Critique of the Judgement of Taste. Cambridge, MA: Harvard University Press, 1984.

Calleja, G. "Digital Game Involvement: A Conceptual Model." Games and Culture 2, 2007: 236-260.

Calleja, G. In-Game: From Immersion to Incorporation. Cambridge, MA: MIT Press, 2011.

Climax Group. Silent Hill: Shattered Memories [Wii], Konami Digital Entertainment, 2009. Played April-May 2010.

Consalvo, M. Cheating: Gaining Advantage in Videogames. Cambridge, MA: MIT Press, 2007.

Egenfeldt-Nielsen, S., J. H. Smith, and S. P. Tosca. Understanding Video Games: The Essential Introduction. New York and London: Routledge, 2008.

Elliott, H. "The Use of Diaries in Sociological Research on Health Experience. Sociological Research Online 2, no. 2, 1997. http://www.socresonline.org.uk/2/2/7.html.

Gee, J. P. What Video Games Have to Teach Us About Learning and Literacy. New York: Palgrave Macmillan, 2004.

Gibson, D., C. Aldrich, and M. Prensky., eds. Games and Simulations in Online Learning: Research and Development Frameworks. Hershey, PA: Information Science Publishing, 2007.

Hazlett, R. L. "Using Biometric Measurement to Create Emotionally Compelling Games." In Game Usability: Advice from the Experts for Advancing the Player Experience, edited by K. Isbister and N. Schaffer,187-206. Burlington, MA: Morgan Kauffman Publishers, 2008.

Iacovides, I. "Exploring the Link between Player Involvement and Learning within Digital Games." Proceedings of the 23rd Conference on Human Computer Interaction, 29-34, Cambridge, UK. 2009.

Iacovides I., J. C. Aczel, E. Scanlon, J. Taylor, and W. I. S. Woods. "Motivation, Engagement and Learning through Digital Games." Journal of Virtual and Personal Learning Environments 2(2), 1-16, 2011 a.

Iacovides, I., J. C. Aczel, E. Scanlon, and W. I. S. Woods. "What Do Players Have to Say about Informal Learning through Games?" Paper accepted for the 14th Biennial Conference of the European Association for Research on Learning and Instruction, University of Exeter, UK, 2011b.

Iacovides, I., J. C. Aczel, E. Scanlon and W. I. S. Woods. "What Can Breakdowns and Breakthroughs Tell Us about Learning and Involvement Experienced during Game-Play?" Proceedings of the 5th European Conference on Games Based Learning, 275-281, Athens, Greece, 2011c.

Iacovides, I. "Digital Games: Motivation, Engagement and Informal Learning." Unpublished Ph.D. thesis, The Open University, UK, 2012.

Isbister, K., K. Höök, J. Laaksolahti, and M. Sharp "The Sensual Evaluation Instrument: Developing a Trans-Cultural Self-Report Measure of Affect." International Journal of Human-Computer Studies 65(4), 2007: 315-328. 
Kivikangas, J. M., I. Ekman, G. Chanel, S. Järvelä, M. Salminen, B. Cowley, P. Henttonen, and N. Ravaja "Review on psychophysiological methods in game research." Proceedings of 1st Nordic Digital Games Research Association Conference, August 16-17, 2010, Stockholm.

Kuutti, K. "Activity Theory as a Potential Framework for Human Computer Interaction Research." In Context and Consciousness: Activity Theory and Human-Computer Interaction, edited by B. A. Nardi, 17-44. Cambridge, MA: MIT Press, 1996.

Lave, J., and E. Wegner. Situated Learning: Legitimate Peripheral Participation. Cambridge University Press, UK, 1991.

Malone, T. W. "Toward a Theory of Intrinsically Motivating Instruction." Cognitive Science: A Multidisciplinary Journal 5, 1981: 333-369.

Malone, T. W., and M. R. Lepper. "Making Learning Fun: A Taxonomy of Intrinsic Motivations for Learning. Aptitude, Learning, and Instruction 3, 1987: $223-$ 253.

Mandryk, R. L, and K. M. Inkpen. "Physiological Indicators for the Evaluation of Colocated Collaborative Play." Proceedings of the ACM Conference on Computer Supported Cooperative Work, 2004: 102-111. Chicago, USA.

Mandryk, R. L., and M. S. Atkins. "A Fuzzy Physiological Approach for Continuously Modeling Emotion During Interaction with Play Environments." International Journal of Human-Computer Studies 6(4), 2007: 329-347.

Marsh, T., P. Wright, and S. Smith. "Evaluation for the Design of Experience in Virtual Environments: Modelling Breakdown of Interaction and Illusion." CyberPsychology and Behaviour 4(2),2001: 225-238.

Neversoft. Guitar Hero 5 [Xbox 360], Activision, 2009. Played May 2010.

Nintendo EAD. Zelda: Twilight Princess [Wii], Nintendo, 2006. Played May 2010.

Nintendo EAD. Mario Kart Wii [Wii], Nintendo, 2008. Played August 2010.

Pelletier, C., and M. Oliver. "Learning to Play in Digital Games." Learning, Media and Technology 31, 2006: 329-342.

Revolution Software. Broken Sword: The Shadow of the Templars (The Director's Cut) [DS],2009. Played June 2010.

Ryan, R. M., C. S. Rigby, and A. Przybylski. "The Motivation Pull of Video Games: A Self-Determination Theory Approach." Motivation and Emotion 30, 2006: 347-365.

Ryan, W., and M. A. Siegel. (2009) "Evaluating Interactive Entertainment Using Breakdown: Understanding Embodied Learning in Video Games." Proceedings of DiGRA' 2009 London, UK. http://www.digra.org/dl/db/09287.38300.pdf (accessed Dec 2012)

Santa Monica Studio. God of War III [Playstation 3], Sony Computer Entertainment, 2010. Played June-July 2010.

$$
--16--
$$


Treyarch. Call of Duty: Black Ops [Multiple platforms], Activision, 2010.

Sharples, M. "Methods for Evaluating Mobile Learning." In Researching Mobile Learning: Frameworks, Tools and Research Designs, edited by G. N. Vavoula, N. Pachler, and A. Kukulska-Hulme, 2009: 17-39. Oxford: Peter Lang Publishing Group.

Stake, R. E. "Case Studies." In Strategies of Qualitative Inquiry, edited by Denzin and Lincoln. 2nd ed. London: SAGE Publications, 2003: 134-164.

Stuart, K. Guardian gamesblog, 2010. http://www.guardian.co.uk/technology/gamesblog/2010/nov/11/games-pc (accessed Aug. 2012).

Squire, K. "Open-Ended Video Games: A Model for Developing Learning for the Interactive Age." In The Ecology of Games: Connecting Youth, Games, and Learning, edited by K. Salen. Cambridge, MA: MIT Press, 2008: 167-198.

Sumo Digital. Doctor Who: The Adventure Games [PC download], BBC Wales, Free UK version, 2010. Played July 2010.

Thatgamecompany. Flower [PS3], Sony Computer Entertainment, 2009. Played July 2010.

Traveller's Tales. Lego Indiana Jones 2: The Adventure Continues [Wii], LucasArts, 2009. Played May-June 2010.

Vavoula, G., M. Sharples, E. Scanlon, P. Lonsdale, and A. Jones. (2005). (2005). Report on Literature on Mobile Learning, Science and Collaborative Activity. Kaleidoscope Network of Excellence. Deliverable D33.2.2, Mobile Learning in Informal Science Settings.

http://halshs.archivesouvertes.fr/view_by_stamp.php?\&halsid=offkbt0u1u5n8roc942pav4f93\&labe $\underline{1=S H S \& l a n g u e=\text { fr\&action todo }=\text { view } \& \text { id }=\text { hal- } 00190175 \& \text { version }=1}$ (accessed Aug 2012)

Yin, R. K. Case Study Research: Design and Methods. SAGE Publications, California, USA., 2009.

Zygna. Farmville. [Social network browser game], Facebook, 2009. Played May-June 2010. 